\title{
老年者の恒常状態法肺拡散能力測定 における生理学的死腔測定の試み
}

\author{
佐々木憲二* 福島 保喜** 水上 陽真** \\ 村井 容子** 田口 悦子***
}

\begin{abstract}
<要 約> 一酸化炭素（約 $0.04 \% \mathrm{CO}$ ) を用いた恒常状態法肺挔散能力 DLco SS を, 正常老年者(男19名, 平均年龄 $67.7 \pm 5.7(1 \mathrm{SD})$ ，女：12名，平均年秢 $71.6 \pm 7.7$ (1SD)) と若年 volunteer (男11名，平均 $22.3 \pm 2.0$ (1SD)）とに执いて測定した. Duco SS 測定時に，終末呼気 CO 濃度を肺胞気濃度とみなすことにより， Bohr の式から得られる $\mathrm{VD} / \mathrm{VT}$ 值は, $\mathrm{CO}$ に関する一種の生理学的死腔と考兄られ，VD と VT との間には次 の回㷌式が兄られた；老年者，VD=0.289VT +0.012 (1S.E；0.027, r ; 0.860), 若年者 $V_{D}=0.303 V T+0.015$ (1S.E；0.022, r ; 0.903). 又, 1-Fex/Fr (=COF), DLco SS (BP-47)/鬲 とは, 1-VD/VT を漸近線とする 双曲線の関係にあることを示した。
\end{abstract}

\section{はじめに}

終末呼気採取装置 endtidal sampler ${ }^{1)}$ を用いた恒常状 態法肺拡散能力 (Drco SS) 值は，患者の負担が少く手 技も簡便であるため短時間に実施できることから，老年 者のルーチンの呼吸機能検査の一つとして適当であると 考えられる。既に我々 ${ }^{2)}$ は，その正常子測值が，分時換 気量 $\dot{V E}$ に関する一次回帰式であらわされることを示し た。

一方，特に正常者において本法における終末呼気濃度 FETco を肺胞気濃度 FAco とみなすことができると，

DLco SS 值の測定の他に, CO に関する生理学的死空 $\dot{V} \mathbf{D}$ あるいは, 死腔一一回換気量比 $\mathrm{VD}_{\mathbf{D}} / \mathrm{V}_{\mathrm{T}}$ を計算する ことができる，我々は，前回報告の時に採択した正常老 年者に扣いて，VD，VD/VT 測定を試み，その意義につ いて考察した。

\section{対象・方法}

正常老年者（男19名，女12名）は，東京都立養育院付 属病院研究検查部呼吸機能室において実施された中から 選び，若年者 volunteer（男11名, 職員, 平均 $22.3 \pm 2.0$

* K. Sasaki : 東大第三内科

** Y. Fukushima, Y. Mizukami, Y. Murai : 東京 都立養育院付属病院呼吸器科

*** E. Taguchi : 同研究検查部呼吸機能検査室 受付日 1979. 5. 18
才）とあわせ，前回報告と同一対象者である. 即ち，正 常老年者は60歳以上で, 呼吸器症状がなく, 胸部レ線上 異常がないか，あっても軽症の肺結核の既往や孤立性円 形陰影を有するだけの者で, 且つ, 側弯・後弯症を伴わ ない老年者を選んだ。更に，スパイロメトリーで，\% $\mathrm{VC}>70 \%, \mathrm{FEV}_{1.0} \%>70 \%, \mathrm{RV} / \mathrm{TLC}(\%)>50 \%$, 血 液ガスでhypoxia のないもの $\left(\mathrm{pao}_{2}>70 \mathrm{mmHg}\right)$, 貧血も 有しない $(\mathrm{Hb}>10.0 \mathrm{~g} / \mathrm{d} l)$ のものに限った。ただし，哭 煙歴は, 上記規準を満たす限り, 除外項目としなかった.

DLco の測定は, Diffusion test (ゴダルト社製), endtidal sampler を用いて，坐位にて十分な安静を保たせ， 2 回実施した。 2 回の測定值のうち、 $\mathbf{V E}$ が $1.0 l / \mathrm{min}$ 以 上の差がみられた時は，2回の測定值をそれぞれ採択 し, $\dot{V}$ E が $1.0 l / \mathrm{min}$ 以下の差しかない時は, $\dot{\mathrm{V}}$ の小さ い方の DLco 值のみを採択した ${ }^{3)}$ 。吸入気は，純 COを 室内気にて混合して約 $0.04 \%$ になる様にし，その都度調 整した。

なお有意差の検定は， $\mathrm{t}$ テストによった。

(計算)

拡散能力 DLco は, 次の式で求められる.

DLco $\mathrm{SS}=($ FICo - Fexco $) \times \dot{\text { VE }} /$ FETCo $\times($ BP -47$)$

Fico : 吸気平均 $\mathrm{CO}$ 濃度:

Fexco : 呼気平均 $\mathrm{CO}$ 濃定

$\mathrm{BP}$ : 大気压 $(\mathrm{mmHg})$

一方 Bohr の式より 
$F_{A} \cdot V_{A}+F_{I} V_{D}=F_{E X} \cdot V_{T}$

$\mathrm{VD}+\mathrm{VA}_{\mathrm{A}}=\mathrm{VT}_{\mathrm{T}}$

$\mathrm{VA}_{\mathrm{A}}$ : 肺胞気量

(3)を(2)に代入して

$F_{A}\left(V_{T}-V_{D}\right)+F_{I} V_{D}=F_{E X} \cdot V_{T}$

$$
\begin{aligned}
& \therefore \quad F A=(F E x V T-F I V D) /(V T-V D) \\
& =\left(F_{E X}-F_{\mathbf{I}} \cdot V_{\mathbf{D}} / V_{T}\right) /\left(1-V_{\mathbf{D}} / V_{T}\right) \\
& =F_{I}\left(F_{E X} / F_{I}-V_{D} / V_{T}\right) /\left(1-\left(V_{D} / V_{T}\right)\right. \\
& =F_{I}\left[\left(1-V_{D} / V_{T}\right)-\left(1-F_{E X} / F_{I}\right)\right] /\left(1-V_{D} / V_{T}\right)
\end{aligned}
$$

今, FET=FA として, (4)式を(1)に代入すると（以下 CO を除く)

DLco $\mathrm{SS}=\dot{\mathrm{VE}}\left(\mathrm{FI}_{\mathrm{I}}-\mathrm{Fex}\right)(1-\mathrm{VD} / \mathrm{VT}) /(\mathrm{BP}-47)$

$$
\times F_{I}\left[\left(1-V_{D} / V_{T}\right)-\left(1-F_{E X} / F_{I}\right)\right]
$$

分母, 分子を FI で除して

$$
\begin{aligned}
= & \dot{V} \mathrm{E}(1-\mathrm{FEx} / \mathrm{FI})(1-\mathrm{VD} / \mathrm{VT}) /(\mathrm{BP}-47) \\
& \times\left[(1-\mathrm{VD} / \mathrm{VT})-\left(1-\mathrm{FEx}_{\mathrm{F}} / \mathrm{F}_{\mathbf{I}}\right)\right]
\end{aligned}
$$

$\therefore \quad$ DLco SS $(\mathrm{BP}-47) / \dot{\mathrm{VE}}$

$$
\begin{aligned}
=(1 & -\mathrm{VD} / \mathrm{VT})\left(1-\mathrm{FEx}_{\mathrm{Ex}} / \mathrm{FI}_{\mathbf{I}}\right) /[(1-\mathrm{VD} / \mathrm{VT}) \\
& \left.-\left(1-\mathrm{FEx} / \mathrm{Fr}_{\mathbf{I}}\right)\right]
\end{aligned}
$$

(5)の左辺は，(1)式より次のようになる.

DLco SS $(\mathrm{BP}-47) / \dot{V}_{\mathrm{E}}=(\mathrm{FI}-\mathrm{FEx}) / \mathrm{FET} \rightarrow \mathbf{x} \cdots 6$

同様に，次のようにそれぞれ，y， $\mathrm{k}$ とおくと，

$$
\begin{aligned}
& 1-\mathrm{FEx} / \mathrm{FI}_{\mathbf{I}}=\mathrm{y} \\
& 1-\mathrm{VD} / \mathrm{VT}_{\mathrm{T}}=\mathrm{k}
\end{aligned}
$$

(6)(7)(8)より 5)は次のようになる

$$
\mathrm{x}=\mathrm{k} \cdot \mathrm{y} / \mathrm{k}-\mathrm{y}
$$$$
\therefore \mathrm{xy} / \mathrm{y}-\mathrm{x}=\mathrm{k}
$$

(9)の式は, $\mathrm{x}$ (横軸), y (縦軸) について, Fig. 1 に 示すよらな双曲線を示し, $\mathrm{k}$ の值はその双曲線の漸近線 となっている.

以上より, Fico, Fexco, Fetco, を求めれば, (6)(7)(8) に代入することにより，6式からは，DLco SS 值，(7) 式から fractional CO uptake (COF; Bates ${ }^{4)}$ のいら, 最も簡単な恒常状態法肺拡散能力の指標), (8)式から は，VD/VT がそれぞれ求められる。

$$
\text { 次に, } \mathrm{VT}=\dot{\mathrm{VE}} / \mathrm{f}
$$

$$
\text { (f: 呼吸数/分) }
$$

$$
\mathrm{V}_{\mathrm{D}}=(1-\mathrm{k}) \times \mathrm{V}_{\mathrm{T}}
$$

によってえられた VT, VD から, mouthpiece と非再呼 吸弁との死腔量 $0.030 l$ をそれぞれ引いて， $\mathrm{VD}^{*}, \mathrm{VT}^{*}$ を 求めた。

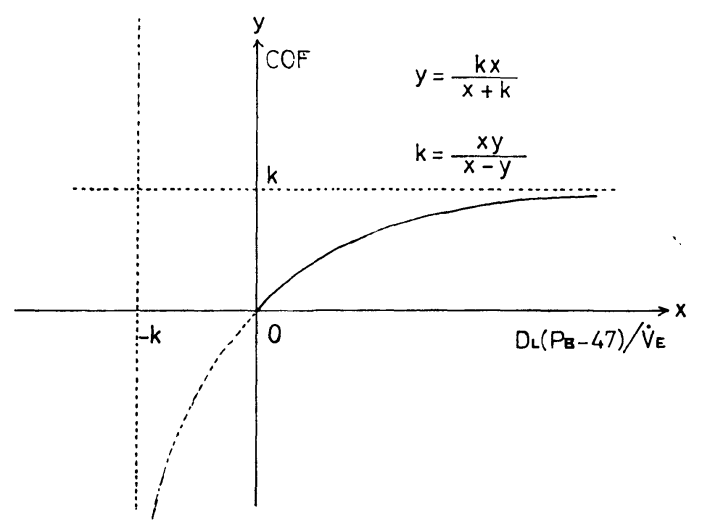

Figure 1 Hyperbolic relationship of DLcoSS (BP47)/VE (axis of abscissa) and COF (axis of ordinate). The two asymptotes are $\mathrm{x}=-\mathrm{k}$ and $\mathrm{y}=$ $\mathrm{k}=1-\mathrm{VD} / \mathrm{VT}$.

\section{結果}

Table 1〜3 にまとめて示してある，测定値，計算值

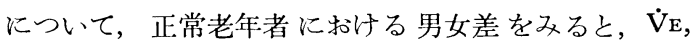
Duco 值はそれぞれ有意差 $(\mathrm{p}<0.05)$ がみられ，同様 に， $\dot{\mathrm{VE}}$ に関連した数值である $\mathrm{VD}, \mathrm{VT}^{*}, \mathrm{VD}^{*}, \mathrm{VD}^{*} / \mathrm{VT}^{*}$ 值も有意差がみられた。しかし, 正常若年者之, 正常 老年者（total）とを比較すると, COF, DLco SS (BP47)/VE に拈いては，有意差 $(\mathrm{p}<0.001)$ を認めた。

次に, 正常老年者について, $\mathrm{VD}^{*}, \mathrm{VT}^{*}$ をプロットし

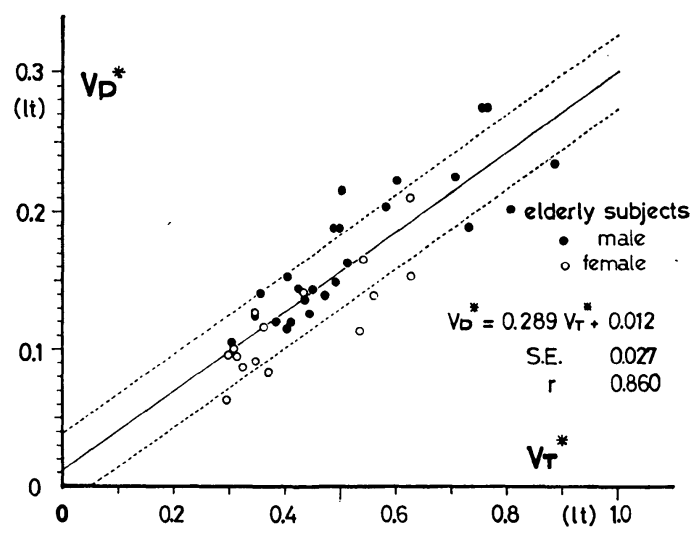

Figure 2 Relationship between respiratory dead space $\left(\mathrm{VD}^{*}\right)$ and tidal volume $\left(\mathrm{VT}^{*}\right)$ subtracted by the apparatus dead space ( 0.030 liter) in elderly persons. Closed circles and open circles are illustrated for males and females, respectively. 
Table 1 Summarized data of the measured and calculated values for normal male elderly persons. $\mathrm{V}_{\mathrm{E}}, \mathrm{V}_{\mathrm{D}}, \mathrm{V}_{\mathrm{I}}^{*}$ and $\mathrm{V}_{\mathrm{T}}^{*}$ are shown in liter.

\begin{tabular}{|c|c|c|c|c|c|c|c|c|c|}
\hline $\begin{array}{l}\text { Bub. } \\
\text { No. }\end{array}$ & $\underset{\text { (liter) }}{\dot{\mathrm{V}}_{\mathrm{E}}}$ & $\mathrm{D}_{\mathrm{Leo}}$ & $\mathrm{CO}_{\mathrm{F}}$ & $\mathrm{D}_{\mathrm{I}}(\mathrm{BP}-47) / \dot{\mathrm{V}}_{\mathrm{E}}$ & $\mathrm{k}$ & $V_{1}$ & $\mathrm{~V}_{D}^{*}$ & $\mathrm{~V}_{\mathrm{T}}^{*}$ & $\mathrm{~V}_{\mathrm{D}}^{*} / \mathrm{V}_{\mathrm{T}}^{*}$ \\
\hline 1 & 11.0 & 19.5 & 0.430 & 1.263 & 0.652 & 0.255 & 0.225 & 0.703 & 0.320 \\
\hline 2 & 7.7 & 7.2 & 0.302 & 0.666 & 0.553 & 0.172 & 0.142 & 0.355 & 0.400 \\
\hline 3 & 7.7 & 11.5 & 0.395 & 1.025 & 0.355 & 0.166 & 0.136 & 0.437 & 0.311 \\
\hline 4 & 6.5 & 6.1 & 0.315 & 0.666 & 0.596 & 0.135 & 0.105 & 0.303 & 0.347 \\
\hline \multirow{2}{*}{5} & 8.2 & 7.1 & 0.304 & 0.615 & 0.600 & 0.252 & 0.222 & 0.601 & 0.469 \\
\hline & 7.0 & 5.4 & 0.282 & 0.549 & 0.579 & 0.218 & 0.188 & 0.489 & 0.384 \\
\hline 6 & 7.5 & 10.5 & 0.398 & 1.000 & 0.662 & 0.169 & 0.139 & 0.470 & 0.296 \\
\hline 7 & 7.4 & 7.9 & 0.316 & 0.757 & 0.536 & 0.245 & 0.215 & 0.499 & 0.431 \\
\hline \multirow{2}{*}{8} & 7.8 & 7.9 & 0.322 & 0.726 & 0.577 & 0.183 & 0.153 & 0.403 & 0.380 \\
\hline & 8.8 & 10.5 & 0.377 & 0.855 & 0.673 & 0.156 & 0.126 & 0.446 & 0.283 \\
\hline 9 & 7.7 & 11.2 & 0.396 & 1.039 & 0.639 & 0.174 & 0.144 & 0.451 & 0.319 \\
\hline \multirow{2}{*}{10} & 10.8 & 10.7 & 0.338 & 0.710 & 0.643 & 0.193 & 0.163 & 0.510 & 0.320 \\
\hline & 7.0 & 6.1 & 0.316 & 0.628 & 0.635 & 0.150 & 0.120 & 0.382 & 0.314 \\
\hline 11 & 6.0 & 8.3 & 0.368 & 1.000 & 0.583 & 0.218 & 0.188 & 0.492 & 0.382 \\
\hline \multirow{2}{*}{12} & 12.1 & 13.6 & 0.379 & 0.800 & 0.722 & 0.232 & 0.202 & 0.804 & 0.251 \\
\hline & 15.1 & 14.3 & 0.346 & 0.675 & 0.711 & 0.264 & 0.234 & 0.885 & 0.264 \\
\hline 13 & 4.5 & 4.9 & 0.443 & 1.094 & 0.745 & 0.143 & 0.113 & 0.533 & 0.212 \\
\hline 14 & 8.8 & 7.2 & 0.295 & 0.589 & 0.590 & 0.154 & 0.124 & 0.344 & 0.360 \\
\hline 15 & 7.9 & 10.9 & 0.380 & 1.175 & 0.614 & 0.305 & 0.275 & 0.760 & 0.362 \\
\hline 16 & 7.7 & 9.1 & 0.372 & 0.853 & 0.659 & 0.150 & 0.120 & 0.410 & 0.293 \\
\hline \multirow{2}{*}{17} & 7.7 & 11.5 & 0.390 & 1.065 & 0.615 & 0.174 & 0.144 & 0.423 & 0.340 \\
\hline & 6.7 & 10.6 & 0.419 & 1.133 & 0.665 & 0.145 & 0.115 & 0.402 & 0.286 \\
\hline \multirow{2}{*}{18} & 8.6 & 9.7 & 0.347 & 0.798 & 0.613 & 0.303 & 0.273 & 0.752 & 0.363 \\
\hline & 6.4 & 7.9 & 0.362 & 0.877 & 0.617 & 0.233 & 0.203 & 0.580 & 0.350 \\
\hline \multirow{2}{*}{19} & 7.6 & 27.1 & 0.494 & 1.612 & 0.712 & 0.219 & 0.189 & 0.730 & 0.259 \\
\hline & 9.9 & 16.9 & 0.427 & 1.224 & 0.657 & 0.179 & 0.149 & 0.491 & 0.303 \\
\hline Mean & 10.2 & 10.2 & 0.366 & 0.900 & 0.634 & 0.200 & 0.170 & 0.525 & 0.327 \\
\hline $\pm S D$ & 3.6 & 3.6 & 0.053 & 0.256 & 0.052 & 0.049 & 0.049 & 0.156 & 0.051 \\
\hline
\end{tabular}

Table 2 Summarized data of the measured and calculated values for normal female elderly persons.

$\mathrm{V}_{\mathrm{E}}, \mathrm{V}_{\mathrm{D}}, \mathrm{V}_{\mathrm{D}}^{*}$ and $\mathrm{V}_{\mathrm{T}}^{*}$ are shown in liter.

\begin{tabular}{|c|c|c|c|c|c|c|c|c|c|}
\hline Sub. & $\dot{\mathrm{V}}_{\mathrm{E}}$ & $\mathrm{D}_{\text {Lco }}$ & $\mathrm{CO}_{\mathrm{F}}$ & $\mathrm{D}_{\mathrm{L}}(\mathrm{BP}-47) / \dot{\mathrm{V}}_{\mathrm{E}}$ & k & $\mathrm{V}_{\mathrm{D}}$ & $\mathrm{V}_{\mathrm{D}}^{*}$ & $\mathrm{~V}_{\mathrm{T}}^{*}$ & $\mathrm{~V}_{\mathrm{D}}^{*} / \mathrm{V}_{\mathrm{T}}^{*}$ \\
\hline \multirow{2}{*}{1} & 7.0 & 8.4 & 0.360 & 0.851 & 0.625 & 0.146 & 0.116 & 0.359 & 0.323 \\
\hline & 6.0 & 8.2 & 0.381 & 0.970 & 0.677 & 0.121 & 0.091 & 0.345 & 0.246 \\
\hline 2 & 6.0 & 5.2 & 0.313 & 0.621 & 0.634 & 0.125 & 0.095 & 0.313 & 0.304 \\
\hline 3 & 5.9 & 6.1 & 0.334 & 0.733 & 0.614 & 0.130 & 0.100 & 0.307 & 0.326 \\
\hline 4 & 7.4 & 6.5 & 0.326 & 0.636 & 0.667 & 0.117 & 0.087 & 0.322 & 0.270 \\
\hline 5 & 6.0 & 4.5 & 0.279 & 0.533 & 0.583 & 0.156 & 0.126 & 0.345 & 0.365 \\
\hline 6 & 7.1 & 10.4 & 0.403 & 1.045 & 0.656 & 0.195 & 0.165 & 0.538 & 0.307 \\
\hline 7 & 5.4 & 5.2 & 0.338 & 0.748 & 0.615 & 0.126 & 0.096 & 0.297 & 0.323 \\
\hline 8 & 7.5 & 10.4 & 0.385 & 0.987 & 0.632 & 0.240 & 0.210 & 0.622 & 0.338 \\
\hline 9 & 6.0 & 6.5 & 0.349 & 0.782 & 0.630 & 0.171 & 0.141 & 0.432 & 0.326 \\
\hline \multirow{2}{*}{10} & 9.4 & 11.7 & 0.395 & 0.886 & 0.712 & 0.168 & 0.139 & 0.558 & 0.249 \\
\hline & 10.8 & 14.5 & 0.411 & 0.995 & 0.721 & 0.183 & 0.153 & 0.625 & 0.245 \\
\hline 11 & 7.4 & 7.1 & 0.351 & 0.685 & 0.718 & 0.113 & 0.083 & 0.370 & 0.224 \\
\hline 12 & 3.9 & 4.7 & 0.390 & 0.906 & 0.715 & 0.093 & 0.063 & 0.295 & 0.214 \\
\hline Mean & 6.7 & 7.7 & 0.353 & 0.810 & 0.644 & 0.180 & 0.119 & 0.409 & 0.291 \\
\hline$\pm \mathrm{SD}$ & 1.7 & 2.9 & 0.039 & 0.153 & 0.048 & 0.045 & 0.039 & 0.123 & 0.046 \\
\hline
\end{tabular}


Table 3 Summarized data of the measured and calculated values for young male volunteers. $\mathrm{V}_{\mathrm{E}}, \mathrm{V}_{\mathrm{D}}, \mathrm{V}_{\mathrm{I}}^{*}$ and $\mathrm{V}_{\mathrm{T}}^{*}$ are shown in liter.

\begin{tabular}{|c|c|c|c|c|c|c|c|c|c|}
\hline Sub. & $\dot{\mathrm{V}}_{\mathrm{E}}$ & $D_{\text {Lro }}$ & $\mathrm{CO}_{\mathrm{F}}$ & $\mathrm{D}_{\mathrm{I}}(\mathrm{BP}-47) / \dot{\mathrm{V}}_{\mathrm{E}}$ & $\mathrm{k}$ & $V_{1)}$ & $\mathrm{V}_{1)}^{*}$ & $\mathrm{~V}_{\mathrm{T}}^{*}$ & $\mathrm{~V}_{\mathrm{I}}^{*} / \mathrm{V}_{\mathrm{T}}^{*}$ \\
\hline 1 & 10.3 & 17.5 & 0.408 & 1.220 & 0.613 & 0.199 & 0.169 & 0.485 & 0.348 \\
\hline \multirow[b]{2}{*}{2} & 9.0 & 24.8 & 0.512 & 1.983 & 0.691 & 0.242 & 0.212 & 0.753 & 0.282 \\
\hline & 6.5 & 17.6 & 0.500 & 1.942 & 0.673 & 0.177 & 0.147 & 0.512 & 0.287 \\
\hline \multirow{2}{*}{3} & 9.7 & 20.8 & 0.437 & 1.520 & 0.613 & 0.242 & 0.212 & 0.596 & 0.356 \\
\hline & 11.0 & 20.4 & 0.426 & 1.314 & 0.640 & 0.214 & 0.184 & 0.549 & 0.355 \\
\hline \multirow{2}{*}{4} & 14.7 & 26.5 & 0.403 & 1.276 & 0.588 & 0.295 & 0.265 & 0.687 & 0.386 \\
\hline & 10.1 & 20.3 & 0.438 & 1.423 & 0.632 & 0.191 & 0.161 & 0.488 & 0.330 \\
\hline \multirow{2}{*}{5} & 7.7 & 17.5 & 0.443 & 1.609 & 0.610 & 0.231 & 0.201 & 0.562 & 0.358 \\
\hline & 6.7 & 16.8 & 0.473 & 1.959 & 0.623 & 0.210 & 0.180 & 0.528 & 0.341 \\
\hline 6 & 7.4 & 13.6 & 0.420 & 1.308 & 0.618 & 0.149 & 0.119 & 0.359 & 0.331 \\
\hline 7 & 9.3 & 18.1 & 0.428 & 1.376 & 0.621 & 0.201 & 0.171 & 0.501 & 0.341 \\
\hline 8 & 6.0 & 22.4 & 0.569 & 2.675 & 0.723 & 0.348 & 0.318 & 0.893 & 0.356 \\
\hline \multirow[b]{2}{*}{9} & 12.3 & 21.8 & 0.417 & 1.273 & 0.620 & 0.234 & 0.204 & 0.585 & 0.346 \\
\hline & 10.2 & 19.6 & 0.443 & 1.378 & 0.653 & 0.186 & 0.156 & 0.507 & 0.308 \\
\hline 10 & 9.0 & 19.7 & 0.457 & 1.568 & 0.645 & 0.178 & 0.148 & 0.470 & 0.315 \\
\hline \multirow{2}{*}{11} & 10.8 & 24.8 & 0.485 & 1.650 & 0.687 & 0.233 & 0.203 & 0.715 & 0.284 \\
\hline & 14.0 & 31.1 & 0.482 & 1.593 & 0.691 & 0.279 & 0.249 & 0.873 & 0.285 \\
\hline Mean & 9.7 & 20.8 & 0.455 & 1.592 & 0.653 & 0.224 & 0.194 & 0.592 & 0.329 \\
\hline$\pm \mathrm{SD}$ & 2.5 & 4.2 & 0.044 & 0.372 & 0.037 & 0.049 & 0.049 & 0.146 & 0.031 \\
\hline
\end{tabular}

Table 4 Summary of regression formulae between $\mathrm{VD}^{*}$ and $\mathrm{VT}^{*} * * *: \mathrm{p} 0.001$ $\mathrm{V}_{\mathrm{D}}^{*}=\mathrm{ax} \mathrm{V}_{\mathrm{T}}^{*}+\mathrm{b} \quad \mathrm{r}$ : regression coefficient

elderly persons

$$
\text { a b ISE } \quad r \quad \text { significano }
$$

$\begin{array}{rlllll}\text { male } & 0.262 & 0.032 & 0.028 & 0.826 & \star \star \star \\ \text { female } & 0.280 & 0.004 & 0.020 & 0.874 & \star \star \star \\ \text { total } & 0.289 & 0.012 & 0.027 & 0.860 & \star \star \star \\ \text { young volunteer } & 0.303 & 0.015 & 0.022 & 0.903 & \star \star \star\end{array}$

て回帰式を求めると, Fig. 2 の通りである. 正常若年者 についてわ同様に回帰式がえられた (Table 4).

\section{考察}

呼吸死腔の測定には, 従来より, $\mathrm{CO}_{2}$ ガスや $\mathrm{N}_{2}, \mathrm{Ar}$ 等の inert gas を indicator として, 呼気の肺胞気組成 によって得られた解剖学的死膑 (Fowler の死腔 ${ }^{5}$ ) と, 動脈血ガス分析により $\mathrm{PaCO}_{2}$ 肺胞気 $\mathrm{CO}_{2}$ 濃度の代わ りに用いることによって得られた生理学的死腔 (Filley

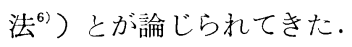

Filley らは, Bohr の式から兄られた VD/VT 值を $\mathrm{PaCO}_{2}, \mathrm{Peco}_{2}$ 值から求めた, 即ち $\mathrm{VD} / \mathrm{VT}=\left(\mathrm{PaCO}_{2}-\mathrm{PeCO}_{2}\right) / \mathrm{PaCO}_{2}$
この VD/VT を(5)式に代入して DLco を求めることが できる、我々の方法による CO 候祭す $V_{D} や V_{D} / V_{T}$ 值は, 指標がス $\mathrm{CO}$ が, 生体には存在しない点や, 呼 吸時に兄られる肺胞気濃度を用いるといら点からは， Fowler 法に近い。しかし， CO が inert ではなく，血 中の $\mathrm{Hb}$ との結びつきは $\mathrm{CO}_{2}$ の場合よりもはるかに強 力で，恒常状態に抢忛るガス交換面の大ささを反映する 点から，VDは一種の生理学的死腔であると考光られ る。

我々の方法により求めた $\mathrm{CO}$ の $\mathrm{VD}, \mathrm{VD}^{*} / \mathrm{VT}^{*}$ ，ある いは, $V_{D}-V_{T}$ の回帰式を, $V_{D}-V_{T}$ の回帰式として 報 告した他の成績と比べてみると，注涪同様の值がえら れた (Table 5)。今回は, Filley 法での $\mathrm{PaCO}_{2}$ による VD/VT 值と比較していないが，（計算）に示すような力 法で VD/VT 值が兄られれば，肺内のガス交換の効率を 窥い知ることの他に, DLCo SS 測定時のsampling error （例えば，VT が大きく，f が小さい場合や mouthpiece の装置の不備等）をはじめ, 測定条件の可否を判定する のに役立つ、のみならず，次にのべるように，DLco 值

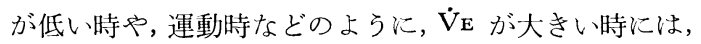
$\mathrm{VD} / \mathrm{VT}$ 值を適当に仮定することにより，COF から直 接計算によって Duco SS 值が求められることになり, FETCO が不正確な条件下汇は，有益である。 
Table 5 Preceding studies on respiratory dead space related to tidal volume with other indicator gases

\begin{tabular}{|c|c|c|c|c|c|c|}
\hline Method & Subjects & Age & $\begin{array}{c}\mathrm{V}_{\mathrm{D}} \text { (range) } \\
\mathrm{ml}\end{array}$ & $\begin{array}{c}\mathrm{V}_{\mathrm{T}} \text { (range) } \\
\mathrm{ml}\end{array}$ & $\mathrm{V}_{\mathrm{D}}-\mathrm{V}_{\mathrm{T}}$ relationship & Investigator (s) \\
\hline $\mathrm{H}_{2}$ & $12\left(80^{7}, 4\right.$ 우 $)$ & $18--39$ & $159(90-260)$ & $501(360-700)$ & $\mathrm{V}_{\mathrm{D}}=0.318 \mathrm{~V}_{\mathrm{T}}$ & Birath, G $(1944)^{8)}$ \\
\hline $\mathrm{N}_{2}$ & 8 (5すㄴ, 3우) & $18-40$ & $189(128-282)$ & $653(462-910)$ & $\mathrm{V}_{\mathrm{D}}=0.30 \mathrm{~V}_{\mathrm{T}}-4.9$ & Bateman, J.B. $(1950)^{9)}$ \\
\hline $\mathrm{N}_{2}$ & 45 (ه্, 우) & $19-38$ & $156(106-219)$ & & & Fowler, W.S. $(1948)^{51}$ \\
\hline $\mathrm{N}_{2}$ & $6(\hat{\delta})$ & $22-60$ & $125(71-156)$ & $552(400-662)$ & & Severinghaus, J.W. $(1955)^{101}$ \\
\hline $\mathrm{CO}_{2}$ & $8(\hat{o})$ & $28-40$ & & & $\begin{array}{l}\mathrm{V}_{\mathrm{D}}=0.199 \mathrm{~V}_{\mathrm{T}} \\
\left(0.12 \mathrm{~V}_{\mathrm{T}} \sim 0.29 \mathrm{~V}_{\mathrm{T}}\right)\end{array}$ & Riley, R.L. $(1949)^{111}$ \\
\hline $\mathrm{CO}_{2}$ & $18(\hat{\delta})$ & $68-89$ & $235(127-370)$ & $492(390-696)$ & & Tenney, S.M. $(1956)^{12)}$ \\
\hline $\mathrm{CO}_{2}$ & $21(\hat{\delta})$ & $21-37$ & 191 & & $\begin{array}{l}\mathrm{V}_{\mathrm{D}}=0.284 \mathrm{~V}_{\mathrm{T}} \\
\left(0.201 \mathrm{~V}_{\mathrm{T}} \sim 0.335 \mathrm{~V}_{\mathrm{T}}\right)\end{array}$ & Jones, N.L. $(1966)^{131}$ \\
\hline
\end{tabular}

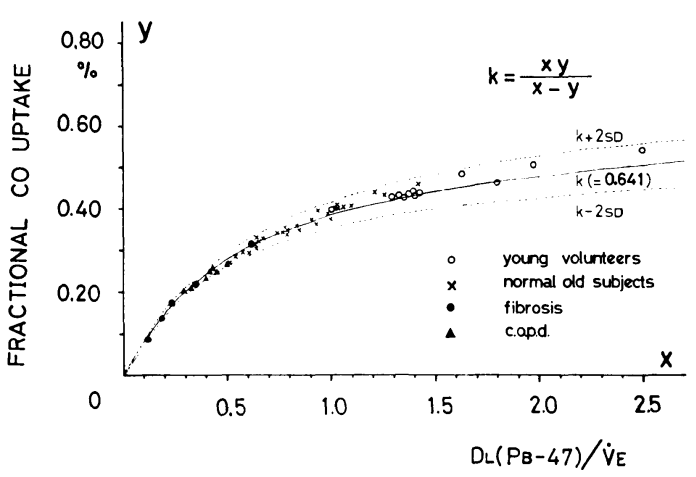

Figure 3 Measured values of DLcoSS (BP-47/VE and $\mathrm{COF}$ in normal elderly persons $(x)$, young male volunteers $(O)$ and some patients of pulmonary fibrosis ( $)$ and chronic obstructive pulmonary disease (COPD) $(\boldsymbol{\Delta})$. Each point is on each line of different $k$ values in Fig. 4. The values of $\mathrm{k}(=0.641)$ is the mean of elderly persons. The dotted lines show $\mathrm{k} \pm 2 \mathrm{SD}$.

\section{$\mathrm{COF}$ と DLco と $\mathrm{VD} / \mathrm{VT}$ との関係:}

(計算)にてのべたように，この3 者の関係は, Fig. 1 に示す通りである.このことは, DLco SS 值が小さい 時や，過換気，運動時などのようにVE が大きくて， Dlco (BP 47)/ن் が小さくなる（座標上左へ動く）時 には， $\mathrm{k}$ の值の変動にかかわらず，双曲線群の変動幅は 小さくなることを示している，逆に，そのような時には $\mathrm{k}$ の值を適当に仮定しても，COF と DLco (BP-47)/ とがよく対応するよらになる。こうして, COF はDLco SS 值のよい指標となるようになり, FETCo が不正確にな るのを補い，FIco な FExco との測定だけで DLco SS 值を計算できる. 試みに, Fig. 3 に, 正常老年者, 若年 者の他に, DLco SS 值が低くなるような数例を, 肺線維 症例や，慢性閉塞性肺疾患患者（COPD）についてプロ
ットしてみると，このことがよく示される.

$\mathrm{COF}$ と D co SS と VD/VT のこの様な関係を明らか にして拉くことにより，上記の他にも，例えば老年者に 時々みられる Cheyne-Stokes 呼吸のように FETco が一 定值をとらず定まらなくても，Texco は求められるの で, 止常老年者で求めた $\mathrm{k}$ (又は VD/VT 值) を仮定し てみることで, COF から DLco SS 值を計算できる. 更に, 運動時にも, COF から直接に DLco SS 值を求 めることができる (West $\left.ら^{7)}\right)$.

謝辞：本研究の機会をお与え下さった都立養育院付属 病院村上元孝院長, 並びに, 御校閲を賜わりました東大 第三内科小坂樹德教授に深謝致します.

\section{文献}

1) Rahn, H. and Otis, A.B.: Continuous analysis of alveolar gas composition during work, hyperpnea, hypercapnia and anoxia, J. Appl. Physiol. 1: 717-724, 1949.

2）佐々木憲二, 福島保喜, 水上陽真他 3 名 : 老年 者の恒常状態法肺桩散能力の正常予測值につい て，日老医会誌 $14: 151-156 ， 1977$.

3）鵜沢 毅, 長田博昭, 磯山凱一他 3 名：慢性肺 疾患者の恒常状態法 CO 肺拡敬能力測定値 の 検討, 日胸疾会誌 $11: 391-400,1973$.

4) Bates, D.V.: The uptake of carbon monoxide in health and in emphysema, Clin. Sci. 11: 21-32, 1952.

5) Fowler, W.S.: Lung function studies II. The respiratory dead space, Amer. J. Physiol. 154: 405-416, 1948.

6) Filley, G.F., MacIntosh, D.J. and Wright, G.W.: Carbon monoxide uptake and pul- 
monary diffusing capacity in normal subjects at rest and during exercise, J. Clin. Invest. 33: $530-539,1954$.

7) West, J.B.: Diffusing capacity of the lung for carbon monoxide at high altitude, J. Appl. Physiol. 17: 42,1-426, 1962.

8) Birath, G.: Lung volume and ventilation efficiency, Act. Med. Scand. Suppl. 154: 114117, 1944.

9) Bateman, J.B.: Studies of lung volume and intrapulmonary mixing. Nitrogen clearance curves; apparent respiratory dead space and its significance, J. Appl. Physiol. 3: 143-160, 1950.

10) Severinghaus, J.W. and Stupfel, M.: Respiratory dead space increase following atropine in man, and atropine, vagal or ganglionic blockade and hypothermia in dogs, J. Appl. Physiol. 8: 81-87, 1955.

11) Riley, R.L. and Cournand, A.: 'Ideal' alveolar air and the analysis of ventilationperfusion relationships in the lungs. J. Appl. Physiol. 1: 825-847, 1949.

12) Tenney, S.M. and Miller, R.M.: Dead space ventilation in old age, J. Appl. Physiol. 9: $321-327,1956$.

13) Jones, N.L., McHardy, G.J.R., Naimark, A. and Campbell, E.J.M.: Physiological dead space and alveolar-arterial gas pressure differences during exercise, Clin. Sci. 31 : 19-29, 1966.

Abstract

\title{
Pulmonary Respiratory Dead Space for Garbon Monoxide with the Measurement of Diffusing Capacity by Steady State in Elderly Persons
}

\author{
Kenji Sasaki*, Yasunobu Fukushima**, Yoshin Mizukami**, \\ Yoko Murai** and Etsuko Taguchi**
}

Pulmonary diffusing capacity (DLcoSS) and fractional $\mathrm{CO}$ uptake (COF) measured with endtidal air sampler in steady state were studied in normal elderly persons over 60 years old including 19 males and 11 females (mean; 67.7 and 71.6, respectively) and in normal young volunteers (mean age; 22.3 y.o.). By

* The Third Department of Internal Medicine, Faculty of Medicine, University of Tokyo, Hogo 7-3-1, Bunkyo-ku, Tokyo

** Pulmonary Division of Internal Medicine, Tokyo Metropolitan Geriatric Hospital, Sakae-cho, Itabashi-ku, Tokyo. assuming endtidal $\mathrm{CO}$ fraction for the mean alveolar in this method, the respiratory dead space $\left(V_{D}\right)$ for carbon monoxide was easily calculated with Bohr's equation and was related to the tidal volume (VT) as follows: $\mathrm{VD}=0.289 \mathrm{VT}+0.012$ (liter: $1 \mathrm{SE} ; 0.027, \mathrm{r}$; 0.860 ) in elderly persons, and $\mathrm{VD}=0.303 \mathrm{VT}+0.015$ (liter: 1SE; 0.022, r; 0.903) in young volunteers. Thus obtained VD is considered as a kind of physiological dead space. Mathematical analysis of the parameters ( $\mathrm{VD} / \mathrm{VT}$, DLcoSS and COF) in this method leads us to comparehend graphycally that DLcoSS (BP-47,/VE and COF are in hyperbolic relation, one of whose asymptotes is $1-\mathrm{VD} / \mathrm{Vr}$. 